\title{
ANTIOXIDANT PHENOLIC COMPOUNDS IN Salvia officinalis L. AND Salvia sclarea $\mathbf{L}$.
}

\author{
PRZECIWUTLENIAJĄCE ZWIĄZKI FENOLOWE \\ W Salvia officinalis L. I Salvia sclarea $\mathbf{L}$.
}

\begin{abstract}
The differences in the chemical composition of the phenolic compounds of Salvia officinalis versus Salvia sclarea growing in different habitats, were studied. First, the optimal solvent - methanol - for ultrasonic extraction of phenolic compounds from these plants was chosen experimentally. Total phenolic content and 1,1-diphenyl-2-picrylhydrazyl (DPPH) assays were determined spectrophotometrically. Total phenolic content was in the range of 63.9 to $134.4 \mathrm{mg} \mathrm{GAE} / \mathrm{g}$ of plant depending on the studied species. The highest antiradical activity was displayed by the methanol fractions of $S$. sclarea varieties (83 and 67\%). HPLC-DAD analysis of extracts was done in order to identify the presence of individual phenolic compounds. This was done by comparison of their retention times with those observed for 17 commercially available standard compounds. The results showed differences in the phenolics composition, with plants collected on Crimean peninsula accumulating more phenolic acids than Polish varieties. In turn, the Polish varieties of sage contain bigger amount of flavonoids in their tissues.
\end{abstract}

Keywords: sage, clary sage, Salvia sclarea L., Salvia officinalis L., phenolic compounds

\section{Introduction}

In recent years, considerable attention is given to the healing powers of many plants. Ethnopharmaceutical studies are directed towards assessing their properties and their applicability in phytotherapy. Of particular interest are antioxidants derived from plants since these compounds play an important role in preventing diseases caused by oxidative stress [1-3], to mention only cancer [4, 5], heart disease [6-9] and aging [10].

Common sage (Salvia officinalis L.) and clary sage (Salvia sclarea L.) belong to the most popular species in the genus Salvia. This sages are used widely as cooking additive, as an ornamental and landscape plant, and in herbal medicine. Quite contrary, clary sage is largely cultivated for medicinal and cosmetic purposes. Health benefits of sage plants are known from ancient times. Commercially available herbal agents containing sage plants are used to treat gastrointestinal disorders and help to absorb nutrients, act as antiemetics and

\footnotetext{
${ }^{1}$ Faculty of Chemistry, University of Opole, pl. M. Kopernika 11, 45-040 Opole, Poland

${ }^{2}$ Institute of Essential Oil and Medicinal Plants, Kievskaya 150, 95493 Simferopol, Crimea, Ukraine

*Corresponding author: izajm@uni.opole.pl
} 
eliminate some symptoms of menopause and estrogen deficiency. In traditional herbal medicine the plant is used as an antihydrotic, spasmolytic, antiseptic, and anti-inflammatory agent. Clary sage plants has a warm, sweet smell, which is helpful in the treatment of neurotics, stress, fear, paranoia, anxiety and depression [11, 12].

Salvia plants contain a number of substances characterized by interesting properties. The analysis of the essential oils of $S$. sclarea inflorescence and leaves has been reported by a number of researchers [3]. The major ingredients of its essential oil appeared to be: camphor, sabinol, $\alpha$-thujone and 1,8-cineole, which exhibit mainly antimicrobial and antibiotic properties [13]. The study also covered the extraction from the seeds of sage. The major components of the extracts of seeds were fatty acids: palmitic, palmitoleic, stearic, oleic, linoleic, linolenic, and arachidic acids. These fatty acids are also responsible for the antioxidant activity $[14,15]$.

Sage plant is well-known as a natural, and one of the richest sources of antioxidants its medicinal value is directly related to this property $[3,15,16]$. Phenolic compounds are commonly considered as being responsible for antioxidant properties of sage plants and for their high and diverse biological activity. Thus, it is important and reasonable to study these components in new varieties of plants.

The chemical composition and biological activities of plant extracts highly depend on their variety and numerous abiotic factors, with temperature, rainfall or season being the most important [17]. In addition, a method used for extraction of these cocktails of compounds significantly influence their composition [18].

Therefore, the purpose of this study was to address several issues. First the selection of optimal ultrasound-assisted extraction procedure (time, solvent) was elaborated. Then, the identification of some phenolic constituents of these extracts (phenolic acids, flavonoids and additionally abscisic acid) was done in order to indicate the differences in profiles. The two most frequent medical herbs of $S$. officinalis and varieties of $S$. sclarea were used in this respect.

\section{Materials and methods}

\section{Reagents}

All chemicals were of analytical grade. Methanol, dibasic sodium phosphate heptahydrate $\left(\mathrm{Na}_{2} \mathrm{HPO}_{4} \cdot 7 \mathrm{H}_{2} \mathrm{O}\right)$, hydrochloric acid and $85 \%$ phosphoric acid were purchased from POCH S.A. (Gliwice, Poland). Six flavonoids (galangin, kaempferol, chrysin, quercetin, myricetin and pinocembrin) as well as 11 phenolic acids (3-hydroxybenzoic acid, 3,4-dihydroxybenzoic acid, p-hydroxybenzoic acid, caffeic acid, vanillic acid, syringic acid, $p$-coumaric acid, chlorogenic acid, rosmarinic acid, ferulic acid, ellagic acid) used as phenolics standards were purchased from Sigma-Aldrich (Poznan, Poland). Additionally a sesquiterpene $( \pm$ )-abscisic acid (Sigma-Aldrich, Poznan, Poland) was also used as standard. Standard stock solutions of each of the standards at a concentration of $0.01 \mathrm{mmol} / \mathrm{dm}^{3}$ in HPLC grade methanol were prepared and stored at $4^{\circ} \mathrm{C}$ protected from light.

\section{Plant material}

Varieties of sage were created and put into production at the Institute of Essential Oil and Medicinal Plants of Ukrainian Academy of Agrarian Sciences in Simferopol. Dried, ground leaves of two varieties of Salvia sclarea, namely C 785 (Ukrainian standard 
variety, cultivar grown from 1967) and new varieties Aj-Todor was examined. For comparative purposes dry leaves of Salvia officinalis commercially available from Polish market were used. They were denoted as samples A and B.

\section{Ultrasonic extraction}

Plant material $(0.5 \mathrm{~g})$ was placed in flasks and treated with $50 \mathrm{~cm}^{3}$ of an appropriate solvent (water, ethanol or methanol). Obtained samples were subjected to ultrasound-assisted extraction. Extraction was carried out for 15, 30, 60, 90, 120, 150 and $180 \mathrm{~min}$. Extraction with methanol was carried out for $300 \mathrm{~min}$, but after $180 \mathrm{~min}$, there was no significant increase in dry mass of the extract. Then, the resulting extracts were gravity filtered to remove solids and concentrated to dryness on a rotary evaporator. The residue was dissolved in $3 \mathrm{~cm}^{3}$ of methanol and used for HPLC analysis. Dry extracts were stored at $-20^{\circ} \mathrm{C}$. Each ultrasonic extraction was performed in triplicate.

\section{Determination of total phenolics content (TPC)}

To determine the TPC of analyzed sage extracts the slightly modified Folin-Ciocalteu method was applied [19, 20]. Briefly, $1 \mathrm{~cm}^{3}$ of plant extract $\left(10 \mathrm{~g} / \mathrm{dm}^{3}\right)($ after $210 \mathrm{~min}$ ultrasonic extraction) was placed into a $10 \mathrm{~cm}^{3}$ volumetric flask and $0.5 \mathrm{~cm}^{3}$ Folin-Ciocalteau (FC) reagent and $1.5 \mathrm{~cm}^{3} 20 \% \quad \mathrm{Na}_{2} \mathrm{CO}_{3}$ solution were added. After refilling with distilled water to the mark and thorough agitation the reaction mixture was left to stand for $120 \mathrm{~min}$ at room temperature and then absorption was measured (Hitachi U-2810 spectrophotometer) at $760 \mathrm{~nm}$ against the blank (water). TPC was expressed in $\mathrm{mg}$ of gallic acid equivalents (GAE/100 g) and was determined as average from three parallel measurements.

\section{Antiradical activity (DPPH Test)}

The antiradical activity of sage extract samples was evaluated by a modified method of Firuzi et al. [21]. Briefly, $1 \mathrm{~cm}^{3}$ of methanolic plant extract $\left(1 \mathrm{~g} / 5 \mathrm{~cm}^{3}\right.$ of methanol) was mixed with $4 \mathrm{~cm}^{3}$ of a methanolic solution of DPPH radicals $(0.1 \mathrm{mM})$. The control test was made with a methanol-lacking extract. The mixture was mixed and allowed to stand in the dark for $30 \mathrm{~min}$. Absorbance was measured at $517 \mathrm{~nm}$ against the blank (methanol). Antiradical activity, AA of the sage extract samples was calculated using the following formula:

$$
\mathrm{AA}=100 \cdot\left(A b s_{\text {control }-} A b s_{\text {sample }}\right) / A b s_{\text {control }}[\%]
$$

where $A b s$ represents the absorbance.

\section{HPLC analysis}

The HPLC analyses of plant extracts were performed using an Ultimate 3000 Dionex HPLC system with photodiode array detector (PDA) and using Chromeleon 6.8 software (Dionex, Sunnyvale, CA, USA). Separations were carried out with reversed phase column Gemini 5u C-18 (Merck, Darmstadt, Germany; 250 x $4.60 \mathrm{~mm}$, particle sized $5 \mu \mathrm{m}$ ), a mobile phase consisted of $0.01 \mathrm{~mol} / \mathrm{dm}^{3}$ aqueous phosphate buffer $\mathrm{pH} 2.5$ (solvent $\mathrm{A}$ ) and methanol (solvent B). Constant solvent flow rate $\left(1 \mathrm{~cm}^{3} / \mathrm{min}\right)$ was applied. The following gradient elution scheme was applied (A/B ratio): 10:90\% $t=0 \mathrm{~min} ; 40: 60 \% t=13.5 \mathrm{~min}$; 90:10\% $t=39 \mathrm{~min} ; 100: 0 \% t=42 \mathrm{~min} ; 10: 90 \% t=55 \mathrm{~min}$. The temperature of the column oven was set at $30^{\circ} \mathrm{C}$. The chromatograms were monitored at 214 and $280 \mathrm{~nm}$, since the 
most of the salvia phenolic compounds show their UV absorption maxima around these two wavelengths. The comparison of UV spectra and retention times with standard compounds enabled the identification of phenolic acids and flavonoids presented in analysed sage extracts. They were quantified against their external standards.

\section{Statistical analysis}

All experiment were repeated in triplicate, except for experiments with absorbance measurement in Folin-Ciocalteau method (two times). The values were expressed as the mean \pm standard deviation (or relative standard deviation, RSD). Standard deviations and RSD were calculated using spreadsheet software $\left(\right.$ Excel $\left.^{\circledR}\right)$.

\section{Result and discussion}

\section{Extraction procedure}

The climatic conditions particularly conducive to the Crimean peninsula crops cause that they are rich in essential oils. Clary sage is one of the plant species grown on a large scale in Institute of Essential Oil and Medicinal Plants in Simferopol because of its expected medicinal properties. It was established that in addition to the essential oils they contain a complex of valuable, biologically active substances. In recent years, the modifications of clary sage were performed in order to obtain raw material abundant in

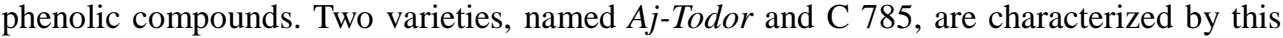
property. Plant phenolic substances reflect in specific antioxidant properties of the sage, and therefore the first objective of this study was to optimize the extraction parameters of phenolic compounds. The first stage of the work focused on the preparation of samples for analysis: optimization of extraction conditions and choice of the most effective solvent.

The kinetics of ultrasonic extraction from aerial parts of common sage (S. officinalis L.) and clary sage (S. sclarea L.) using water, ethanol or methanol was studied at the solid-to-liquid ratio of $1: 10(\mathrm{w} / \mathrm{v})$, at room temperature $\left(20^{\circ} \mathrm{C}\right)$ and at $40^{\circ} \mathrm{C}$. The change of dry mass extracts with the progress of ultrasonic extraction is shown in Table 1 and Figure 1. It is clearly visible that methanol is a solvent of choice for extraction.

Table 1

Comparison of the mass of dry extract obtained from tested plants under different extraction conditions

\begin{tabular}{|c|c|c|c|c|c|c|c|c|c|c|c|c|c|c|c|c|c|c|c|c|c|c|c|c|}
\hline \multicolumn{25}{|c|}{ Mass of dry extract [mg/g plant material] $(\mathrm{RSD} \leq 5 \%, n=3)$} \\
\hline & \multicolumn{6}{|c|}{$\begin{array}{l}\text { S. sclarea } \\
\text { Aj-Todor }\end{array}$} & \multicolumn{6}{|c|}{$\begin{array}{l}\text { S. sclarea } \\
\text { C } 785\end{array}$} & \multicolumn{6}{|c|}{$\begin{array}{c}\text { S. officinalis } \\
A\end{array}$} & \multicolumn{6}{|c|}{$\begin{array}{c}\text { S. officinalis } \\
\text { B }\end{array}$} \\
\hline \multirow{2}{*}{$\begin{array}{l}\text { Extraction } \\
\text { time [min] }\end{array}$} & \multicolumn{3}{|c|}{$20^{\circ} \mathrm{C}$} & \multicolumn{3}{|c|}{$40^{\circ} \mathrm{C}$} & \multicolumn{3}{|c|}{$20^{\circ} \mathrm{C}$} & \multicolumn{3}{|c|}{$40^{\circ} \mathrm{C}$} & \multicolumn{3}{|c|}{$20^{\circ} \mathrm{C}$} & \multicolumn{3}{|c|}{$40^{\circ} \mathrm{C}$} & \multicolumn{3}{|c|}{$20^{\circ} \mathrm{C}$} & \multicolumn{3}{|c|}{$40^{\circ} \mathrm{C}$} \\
\hline & W & $\mathrm{M}$ & $\mathrm{E}$ & $\mathrm{W}$ & $\mathrm{M}$ & $\mathrm{E}$ & $\mathrm{W}$ & $\mathrm{M}$ & $\mathrm{E}$ & $\mathrm{W}$ & $\mathrm{M}$ & $\mathrm{E}$ & W & M & $\mathrm{E}$ & $\mathrm{W}$ & $\mathrm{M}$ & $\mathrm{E}$ & $\mathrm{W}$ & $\mathrm{M}$ & $\mathrm{E}$ & $\mathrm{W}$ & $\mathrm{M}$ & $E$ \\
\hline 5 & 57 & 150 & 123 & 71 & 230 & 191 & 65 & 193 & 165 & 83 & 270 & 220 & 46 & 134 & 115 & 53 & 186 & 123 & 45 & 112 & 89 & 48 & 169 & 100 \\
\hline 15 & 67 & 180 & 153 & 74 & 260 & 223 & 67 & 193 & 184 & \begin{tabular}{|l|}
84 \\
\end{tabular} & 275 & 248 & 47 & 138 & 117 & 55 & 200 & 126 & 43 & 118 & 91 & 50 & 192 & 105 \\
\hline 30 & 68 & 197 & 153 & 86 & 277 & 240 & 75 & 210 & 190 & 103 & 283 & 256 & 50 & 142 & 120 & 57 & 221 & 129 & 46 & 129 & 94 & 50 & 209 & 105 \\
\hline 60 & 71 & 202 & 186 & 88 & 290 & 267 & 80 & 220 & 185 & 110 & 305 & 282 & 49 & 150 & 120 & 58 & 238 & 130 & 48 & 143 & 95 & 52 & 211 & 107 \\
\hline
\end{tabular}

Ss - S. sclarea, So - S. officinalis, W - water, M - methanol, E - ethanol

As seen from Figure 1 two periods of extraction can be observed independently on plant species and extraction temperature. First is characterized by a rapid increase in the mass of dry extract at the beginning of the process, and second slow extraction (approximately after the first $5 \mathrm{~min}$ ) is characterized by a slow increase in the extract mass 
along the progress of extraction. The optimum time for ultrasonic extraction can be set at 15 min since it ensures nearly the maximal mass of dry extracts.

Data shown in Figure 1 and Table 1 disclose that both plant species contain hydrophilic substances preferably soluble in methanol. By comparing the level of dry mass of the two species, one can notice that it is higher in both varieties of S. sclarea $\mathrm{L}$.

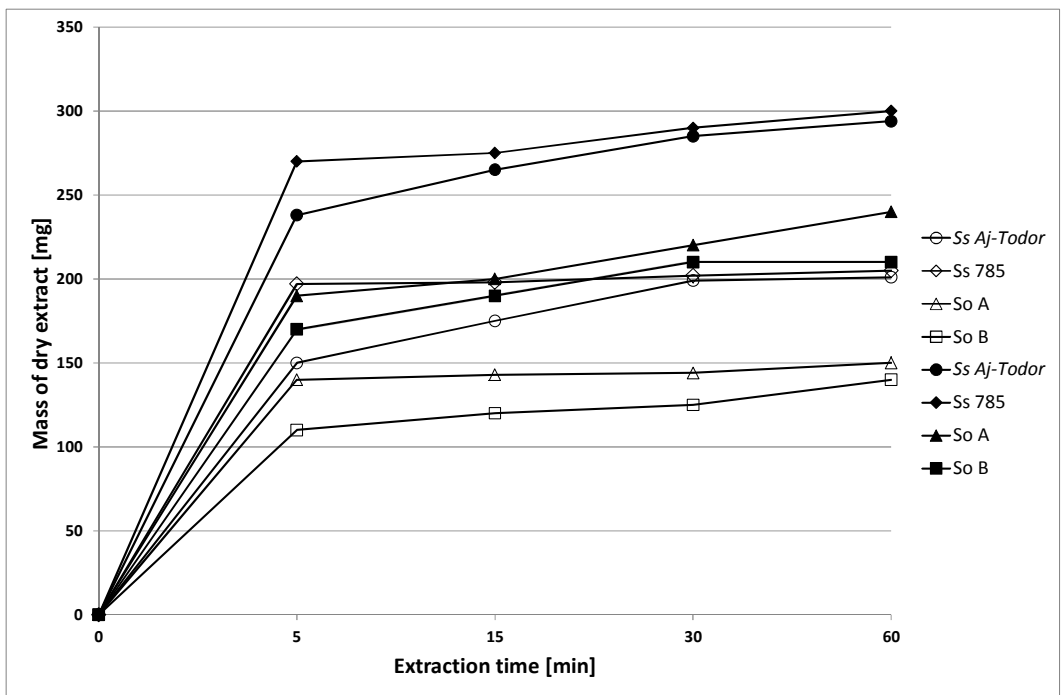

Fig. 1. Variation of mass of dry extract with sonication time and different temperatures of extractions with methanol (Ss - S. sclarea, So - S. officinalis; open symbols $-20^{\circ} \mathrm{C}$, black symbols $-40^{\circ} \mathrm{C}$ )

\section{Total phenolic content (TPC) and antioxidant activity}

Phenolic compounds are widely distributed in nature, particularly large amounts of these substances are synthesized in plant tissues. It is assumed, that due to the presence of hydroxyl groups in their structure they exhibit antioxidant properties. Hence, it is important to determine the total amount of these compounds in plant samples as it indicates the possibility of their medicinal use. Thus, all methanolic extract (S. sclarea and S. officinalis) were screened for their content of phenolic compounds by the Folin-Ciocalteu reagent. The obtained values of TPC are shown in Table 2. As can be seen, varieties of the Crimean peninsula contain higher level of phenolic compounds, with the highest being in $S$. sclarea var. 785 reaching $134.4 \mathrm{mg} \mathrm{GAE} / \mathrm{g}$ extract.

Content of phenolic compounds in tested Salvia

\begin{tabular}{|c|c|c|}
\hline Sample name & $\begin{array}{c}\text { TPC } \\
\text { [mg GAE/g d.m.] } \\
\pm \mathrm{RSD}, n=3\end{array}$ & $\begin{array}{c}\text { DPPH } \\
{[\%]} \\
\pm \text { RSD, } n=3\end{array}$ \\
\hline S. sclarea C 785 & $134.4 \pm 9.7$ & $83.4 \pm 3.7$ \\
\hline S. sclarea Aj-Todor & $96.1 \pm 2.6$ & $67.7 \pm 2.1$ \\
\hline S. officinalis (A) & $93.8 \pm 3.1$ & $60.9 \pm 2.9$ \\
\hline S. officinalis (B) & $63.9 \pm 2.9$ & $41.5 \pm 3.1$ \\
\hline
\end{tabular}

GAE - gallic acid equivalent 
The antioxidant activity of Salvia species was determined using the DPPH radical scavenging activity method. The results of DPPH radical scavenging activity are listed in Table 2. Among the methanolic extracts of the studied species, S. sclarea showed a better scavenging activity against DPPH.

Tested Salvia spp. was proved to be a good source of polyphenolic compounds with high antioxidant potential.

\section{Profiles of phenolic compounds in sage extracts}

Study the chemical composition of medicinal plants traditionally used in medicine is important for anticipating and interpretation of their potential biological performance. Literature indicates that most studies on sage plants mainly focuses on their essential oils $[3,18]$. However, in recent years, much attention has been also directed towards biologically active, hydrophilic constituents $[15,16]$.

Phenolic acids and flavonoids are well-known from their antioxidant properties, with derivatives of benzoic acid and hydroxycinnamates showing their antioxidant activities by hydrogen-donating mechanism [22, 23].

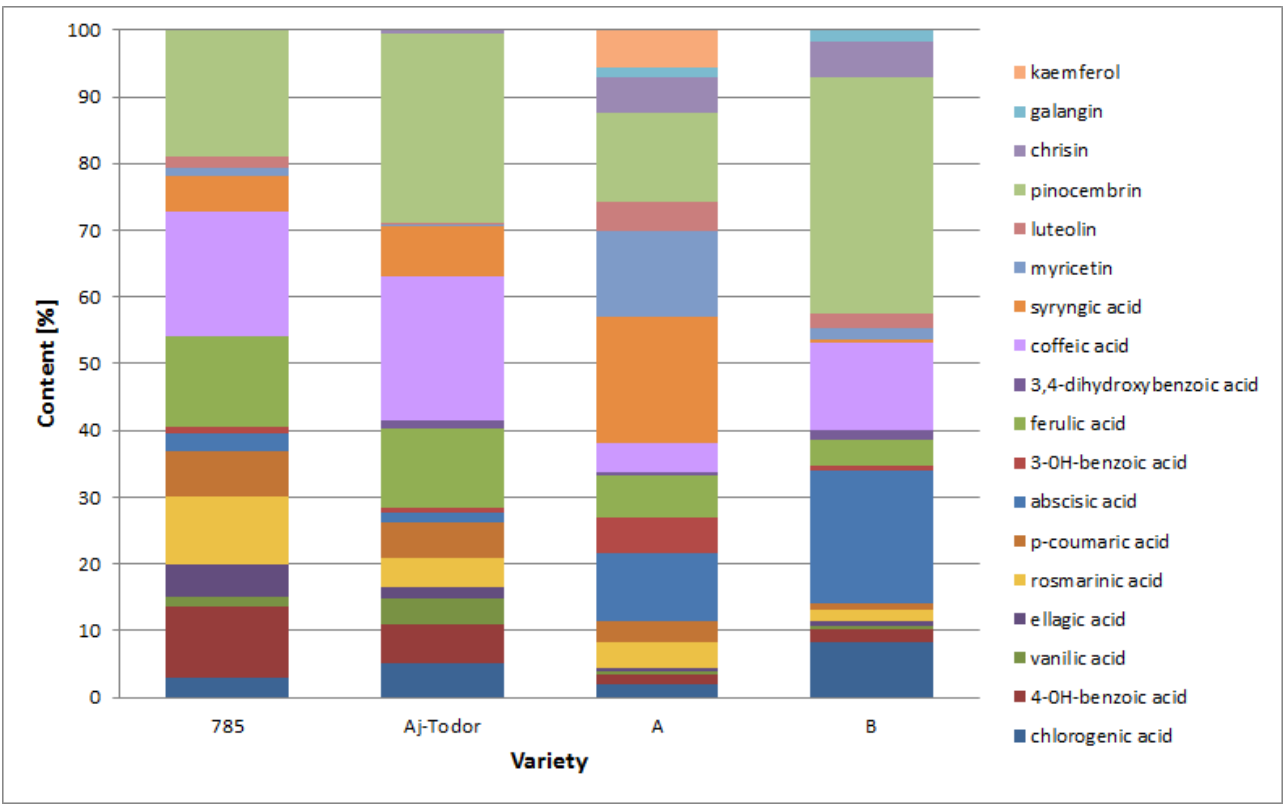

Fig. 2. Profiles of phenolic compounds and abscisic acid in S. sclarea (C 785, Aj-Todor) and S. officinalis (A, B) varieties

This study aimed to evaluated the phenolic profile (phenolic acids, flavonoids, and additionally abscisic acid) in two new varieties of $S$. sclarea and two commercially available varieties of $S$. officinalis (denoted as samples A and B). The total phenol and flavonoid contents in sage extracts were determined spectrophotometrically, while the principal phenolics were determined using HPLC-RP-DAD. Compositions of the extracts obtained from $S$. sclarea L. and S. officinalis L. varieties are presented in Figure 2. Using 
internal standards, eighteen phenolic compounds were identified in the extracts of S. sclarea and S. officinalis. They include eleven phenolic acids (3-hydroxybenzoic acid, 3,4-dihydroxybenzoic acid, $p$-hydroxybenzoic acid, caffeic acid, vanillic acid, syringic acid, p-coumaric acid, chlorogenic acid, rosmarinic acid, ferulic acid, ellagic acid), and six flavonoids (galangin, kaempferol, chrysin, luteolin, myricetin and pinocembrin) (Fig. 2).

This is not surprising because the presence of phenolic acids and flavonoids is well documented in the literature [18, 24-27]. The obtained profiles clearly show that aerial parts of sage of Crimean varieties contain larger amounts phenolics than Polish varieties. Furthermore, as shown in Figure 2, the profiles of phenolic compounds present in the two varieties of $S$. sclarea are almost identical, whereas Polish varieties of $S$. officinalis are characterized by a much greater diversity.

Phenolic acids represent above $70 \%$ of the total identified phenolic compounds present in S. sclarea Crimean samples (Fig. 3). In turn, extracts from S. officinalis contained between $55-60 \%$ of the tested phenolic acids. Analysis of the composition of phenolic acids shows domination of caffeic and ferulic acid in S. sclarea varieties, where much lower contents of these compounds were detected in S. officinalis. In turn, an isoprenoid $( \pm)$-abscisic acid appeared in significantly high level in two $S$. officinalis extracts (Figs. 2 and 3). Although being an isoprenoid abscisic acid, like phenolic acids, shows very strong UV absorbance at $290 \mathrm{~nm}$. Once more, the differences in composition of these compounds between Polish sages appear to be significant.

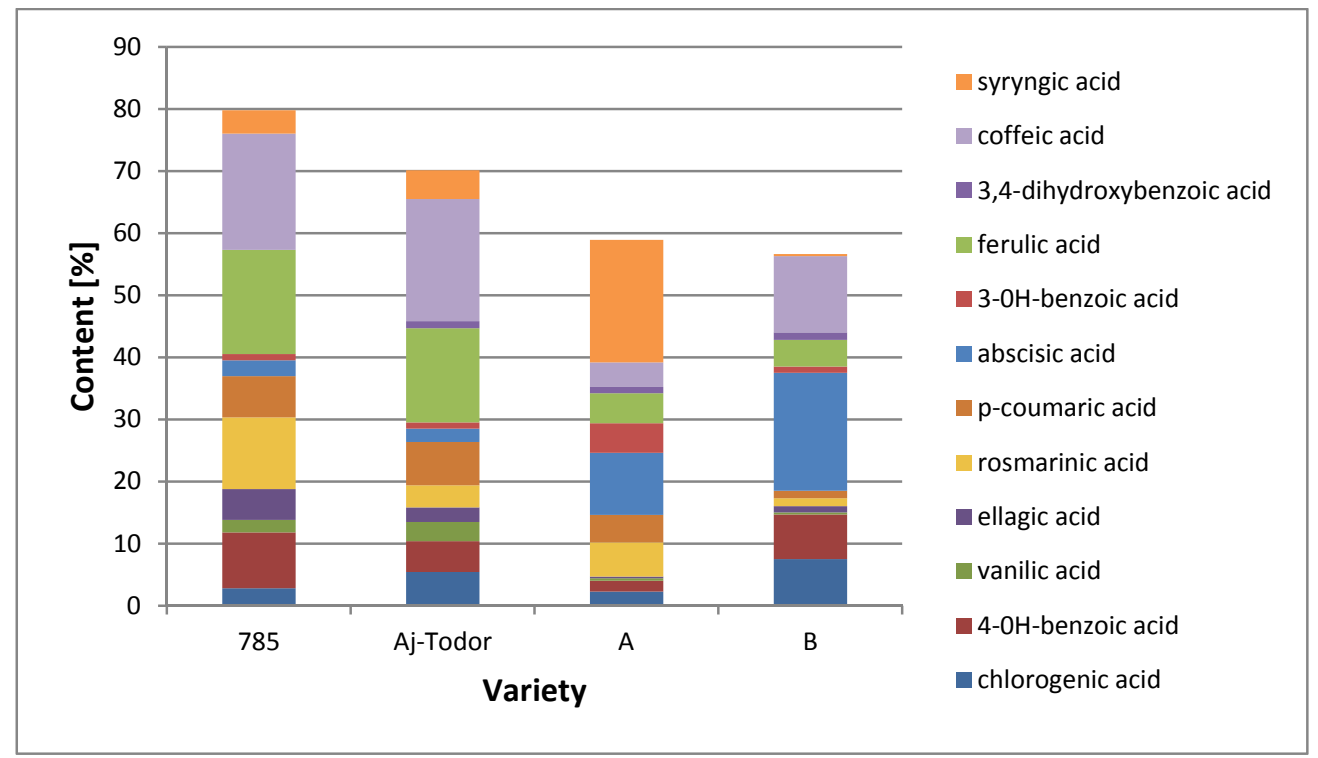

Fig. 3. Profiles of phenolic acids and abscisic acid in $S$. sclarea (C 785, Aj-Todor) and S. officinalis $(\mathrm{A}, \mathrm{B})$ varieties

The remaining components, which were flavonoids care present at a level of about $20-30 \%$ in S. sclarea and 40-45\% in S. officinalis samples (Fig. 4). Thus Polish sages are visibly reacher in flavonoids considering both their relative level and structural variability. Pinocembrin appeared to be major component of flavonoid fraction in both, S. sclarea and 
S. officinalis. Although the highest level of this flavonoid was observed in the extract obtained from the $S$. officinalis denoted as sample B (above 35\%) it is worth no note that this compound is nearly sole component of flavonoid fraction of S. sclarea. Among the six available standards of flavonoids, only four were observed in Aj-Todor variety.

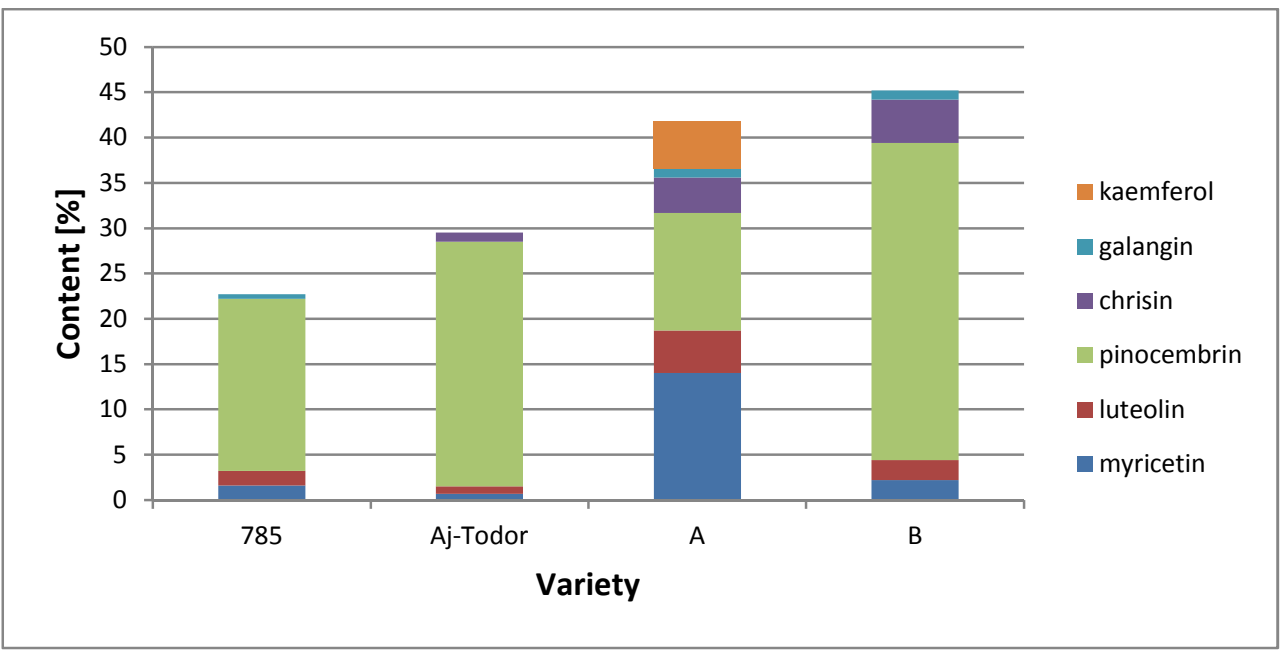

Fig. 4. Profiles of flavonoids in S. sclarea (C 785, Aj-Todor) and S. officinalis (A, B) varieties

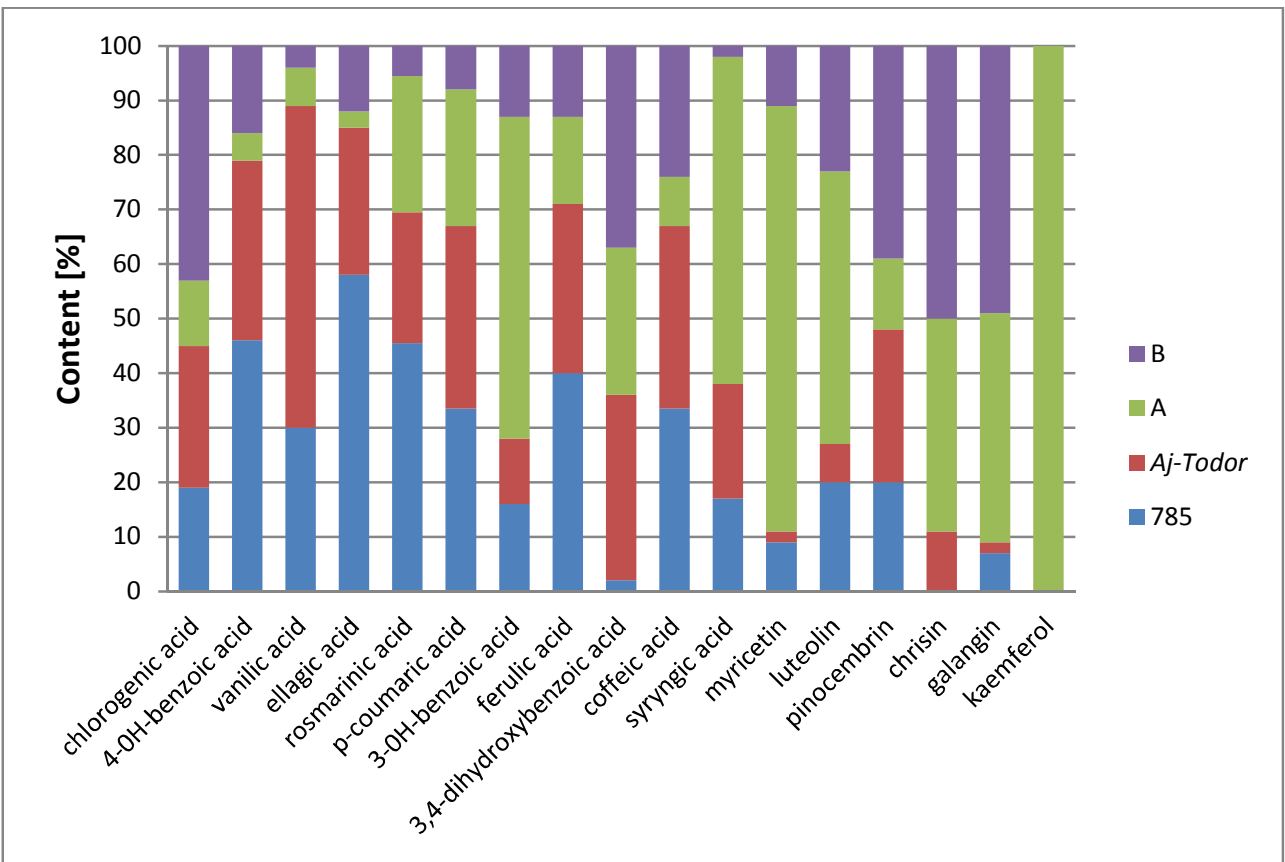

Fig. 5. Participation of detected phenolic compounds in the tested varieties of sage (S. sclarea and S. officinalis) 
The composition of flavonoid fraction of S. officinalis (variety A) differs significantly from three remaining species and is characterized by substantially large amounts of myricetin (above 14\%). Figure 5 clearly indicates that every variety of sage studied in this work are characterized by specific profile of phenolic compounds. For example, S. officinalis variety (denoted as sample A) contains kaemferol, which is absent from other species. Thus, the profile of certain variety might be considered as its finger-print. However, such an assumption requires further studies.

\section{Conclusions}

The present study has confirmed that HPLC with PDA detector detection is a useful tool for the identification and quantification of phenolic compounds in a complex matrix like sage extracts. Consequently, several phenolic acids, flavonoids and abscisic acid were quantified in two Salvia species.

It is well known that many factors such as geographical, ecological, and climatic alongside with genetic factors are responsible for observed intraspecific variability of chemical composition of plant varieties. These factors significantly influence the plant growth and development, their biosynthetic pathways, and thus regulate the content of specific chemical secondary metabolites.

At first sight, it is possible to notice significant differences in HPLC phenolics profiles among extracts of Salvia samples, which represent the same type of botanical origin and differ in geographical origin. Variations from the Crimean peninsula contain significantly less flavonoid compounds, but in turn produce significant amounts of phenolic acids.

The obtained results suggest that the methanolic extracts of new varieties of $S$. sclarea, especially var. 785, was proved to be a good source of phenolic compounds with high antiradical potential. Salvia spp. extracts may be used as natural source of these compounds in functional food, in cosmetic or as a useful source for pharmaceutical industry.

\section{References}

[1] Grzegorczyk A, Matkowski H, Wysokińska H. Food Chem. 2007;104:536-541. DOI: 10.1016/j.foodchem.2006.12.003.

[2] Tepe B, Sokmen M, Akpulat HA, Sokmen A. Food Chem. 2007;95:200-204. DOI: 10.1016/j.foodchem.2004.12.031.

[3] Farhat MB, Jordan MJ, Chaouech-Homada R, Landoulsi A, Sotomayor JA. J Agric Food Chem. 2009;57:10349-10356. DOI: 10.1021/jf901877x.

[4] Alasalvar C, Karamac M, Amarowicz R, Shahidi F. J Agric Food Chem. 2006;54:4826-4832. DOI: 10.1021/jf0601259.

[5] Ulubelen A. Phytochemistry. 2003;64:395-399. DOI: 10.1016/S0031-9422(03)00225-5

[6] Khan MA, Baseer A. J Pak Med Assoc. 2000;50:261-264. http://jpma.org.pk/ full_article_text.php?article_id=3059.

[7] Stocker R, Keaney JF Jr. Physiol Rev. 2004;84:1381-1478. DOI: 10.1152/physrev.00047.2003.

[8] Madamanchi NR, Vendrov A, Runge MS. Arterioscler Thromb Vasc Biol. 2005;25:29-38. DOI: 10.3390/ijms140917319.

[9] Grassi D, Desideri G, Croce G, Tiberti S, Aggio A, Ferri C. Curr Pharm Des. 2009;15:1072-1084. DOI: $10.2174 / 138161209787846982$.

[10] Sastre J, Pallardo FV, Vina J. IUBMB Life. 2000;49:427-435. DOI: 10.1080/152165400410281.

[11] Kamatou GP, Makunga NP, Ramogola WP, Viljoen AM. J Ethnopharmacol. 2008;119:664-672. DOI: 10.1016/j.jep.2008.06.030.

[12] Hao DC, Gu XJ, Xiao PG. Phytochemical and biological research of Salvia medicinal resources. In: Hao DC, Gu XJ, Xiao PG, editors. Medicinal Plants Chemistry, Biology and Omics. Cambridge: Woodhead Publishing; 2015. ISBN 978-0-08-100085-4. 
[13] Ozkan G, Sagdic O, Gokturk RS, Unal O, Albayrak S. LWT - Food Sci Technol. 2010;43:186-190. DOI: 10.1016/j.lwt.2009.06.014.

[14] Diwakar G, Rana J, Saito L, Vredeveld D, Zemaitis D, Scholten J. Fitoterapia. 2014;97:164-171. DOI: 10.1016/j.fitote.2014.05.021.

[15] Loizzo MR, Abouali M, Salehi P, Sonbolic A, Kananic M, Menichinia F, et al. Nat Prod Res. 2014;28:2278-2285. DOI: 10.1080/14786419.2014.939086.

[16] Medjahed F, Merouane A, Saadi A, Bader A, Cioni PL, Flamini G. Chilean J Agric Res. 2016;76:195-200. DOI: $10.4067 /$ S0718-58392016000200009.

[17] Generalic I, Skroza D, Ljubenkov I, Katalinic A, Burcul F, Katalinic V. Food Chem. 2011;127:427-433. DOI: 10.1016/j.foodchem.2011.01.013.

[18] Durling EN, Catchpole OJ, Grey JB, Webby RF, Mitchell KA, Foo LY, et al. Food Chem. 2007;101:1417-1424. DOI: 10.1016/j.foodchem.2006.03.050.

[19] Lu Y, Foo LY. Phytochemistry. 2002;59:117-140. https://ac.els-cdn.com/S0031942201004150/ 1-s2.0-S0031942201004150-main.pdf?_tid=d85c73e0-22d1-4b58-b094-2c893cc37f85\&acdnat= 1520191611_1559a530f2aeff45570427c0509f54fc.

[20] Kosar M, Göger F, Baser KHC. J Agric Food Chem. 2008;56:2369-2374. DOI: 10.1021/jf073516b.

[21] Firuzi O, Miri R, Asadollahi M, Eslami S, Jassbi AR. Iran J Pharm Res. 2013;12:801-810. https://www.ncbi.nlm.nih.gov/pmc/articles/PMC3920696/pdf/ijpr-12-801.pdf.

[22] Beretta G, Granata P, Ferrero M, Orioli M, Maffei Facino R. Anal Chim Acta. 2005;533:185-191. DOI: 10.1016/j.aca.2004.11.010.

[23] Socha R, Juszczak L, Pietrzyk S, Gałkowska D, Fortuna T, Witczak T. Int J Food Sci Technol. 2011;46:528-534. DOI: 10.1111/j.1365-2621.2010.02517.x.

[24] Orhan IE, Senol FS, Ercetin T, Kahraman A, Celep F, Akaydin G, et al. Ind Crop Prod. 2013;41:21-30. DOI: 10.1016/j.indcrop.2012.04.002.

[25] Stagos D, Portesis N, Spanou C, Mossialos D, Aligiannis N, Chaita E, et al. Food Chem Taxicol. 2012;50:4115-4124. DOI: 10.1016/j.fct.2012.08.033.

[26] Jeshvaghani ZA, Rahimmalek M, Talebi M, Goli SAH. Indust Crops and Products 2015;77:409-414. DOI: 10.1016/j.indcrop.2015.09.005.

[27] Yumrutas O, Sokmen A, Ozturk N. J Appl Pharm Sci. 2011;1:43-46. https://pdfs.semanticscholar.org/0722/d0b652ae077382fd75a8e1a8ad2b4a2b11c4.pdf. 